\title{
THE EFFECT OF WATER STRESS ON PHOSPHATIDYLCHOLINE COMPOSITION IN DURUM WHEAT LEAVES
}

\author{
BOUHOUHOU Mouloud ${ }^{1 *}$, BENSARI Mourad ${ }^{2}$ \\ ${ }^{1 *}$ M. Bouhouhou, ENS Assia DJebar, Constantine, Algeria; \\ ${ }^{2}$ M. Bensari, Mentouri University, Constantine, Algeria;
}

"Corresponding author BOUHOUHOU Mouloud, e-mail: bouhouhoumouloud@gmail.com;

Received June 2019; Accepted August 2019; Published October 2019;

DOI: https://doi.org/10.31407/ijees9414

\begin{abstract}
Two durum wheat (Triticum durum Desf) cultivars, Oued-Zenati 368 (OZ) and Kebir (K), differently sensitive to drought are cultivated under controlled conditions. The PEG is used at the $21^{\text {st }}$ day of the plantation in order to obtain a moderate level of water stress (S). At the $28^{\text {th }}$ day, the relative water content (RWC) and the leaf phosphatidylcholine (PC) composition were studied in the controlled and stressed plants. The water stress provokes a reduction of RWC in the two cultivars, and the amount of $\mathrm{PC}$ increase in $\mathrm{OZ}$ and decrease in $\mathrm{K}$. We also examined the composition of fatty acids for this phospholipid, and the changes provoked in the degree of unsaturation (DoU) by the water stress. Our results confirm the settled hypothesis: that we could exploit phosphatidylcholine as biological marker for the screening of the plant genotypes resistant to the drought.
\end{abstract}

Keywords: Degree of unsaturation, fatty acids, phosphatidylcholine, Triticum durum Desf, water stress. 